\title{
Libraries, Language, and Change: Defining the Information Present
}

\section{Harold Billings}

Changes in the information world are resulting in new concepts of resource sharing, new practices in the management of library resources, and an expanding role for libraries in the educational process. However, such concepts have not necessarily been identified, named, and defined in the language of contemporary librarianship. Although librarians and their associates in the information and educational processes need to be made aware of these subtle, but powerful, new issues, discussions cannot easily proceed until there is a shared understanding of them in the language of review and debate. This paper introduces three themes that encompass these issues: distance information, managed information, and transformational budgeting.

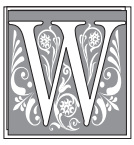

hat we call things affects how well we understand them. Until things are widely named and defined, they resist broad study and common understanding. The El Niño meteorological effect is a case in point. The need for fresh library naming and definition is particularly important during this time of paradigmatic change. Librarians have created more contemporary metaphors for libraries in their attempts to clarify what libraries either are or may become during this metamorphosis. The term digital library is an excellent example. However, a vocabulary for major concepts of change has not been given the same attention.

A few years ago, the author attempted to compare the knowledge systems of the sixteenth century with those of the present, suggesting that there was an opportunity for a new orderliness in libraries that could best be understood by comparing the image-based, magic memory systems of those earlier information seekers with modern computing and contemporary information systems. ${ }^{1}$ One wanted, it was affirmed, to employ fresh language and images as magical as any of the sixteenth century in attempting to find new order in the structure and complexity of the natural world, to bring new dimensions to the sciences we know.

More recently, Peter Lyman, university librarian at the University of CaliforniaBerkeley, has said: “We always talk about new technology using old vocabulary ... 'Electronic publishing,' 'digital library,' 'information highway': to our grandchildren these terms will probably sound as peculiar as 'horseless carriage."'2 The occasion of his comment was a gathering at the New York Public Library in April 1996 of fifty distinguished library leaders from around the world. The general theme of the meeting was the redefinition of the 
library's role in the digital age. According to Lyman's quoted account, the meeting involved a great deal of "linguistic fumbling." This was likely due to efforts to attach the discussion to a topic that already had moved beyond a language of collective comprehension. Ideas and issues can be exchanged only if the images conjured from the language of choice achieve some common understanding in the cognitive process.

Ideas and issues can be exchanged only if the images conjured from the language of choice achieve some common understanding in the cognitive process.

There are new activities, initiatives, and dynamics in librarianship that are becoming recognizable, but they have not yet been named in a manner that permits their discussion on a broad, commonly understood basis. In other words, they are not yet a part of our library language. Defining these concepts may help us understand the changing information environment that envelops our libraries and may improve our steerage of them through a transformational passage into the information future. Examples of emerging themes to position in our language include distance information, managed information, and transformational budgeting, discussed later.

\section{Technical and Educational Background}

A review of the transforming information and educational environments can help clarify the forces producing these emerging new themes. Few areas of library effort have escaped the tremblings of the information upheaval. These same instabilities have had an impact on time and distance, affecting their role in information access and delivery. Moreover, they are affecting the very foundations of the educational process.
Until information is needed, it does not matter where it resides. Geography is of little consequence except when it involves the delivery of library materials from traditional collections. The location of digital information servers is insignificant. Thus, if distance is not dead, it certainly is dying. Every hypertext location is immediately present to any other location, every document is a proximate one to the other, every visitor to the Web is in virtual assemblage. In cyberspace, all roads lead to a digital Rome.

Although time is still an important factor, library clocks may be set by zones completely different from Greenwich mean time, solar time, and variegations based on arbitrary geographic boundaries and the seasons of the year. A colleague recently commented that projected revisions of college and university library standards were estimated for completion in about five years but remarked that this was an estimate based on "ALA time."

An announcement reporting the likely release date of a computer upgrade acknowledged that with the rapid changes in "Web time," it was becoming increasingly difficult to assert dates certain or to determine when frequent upgrades to software would quickly leave applications and equipment obsolescent. Many systems and applications seem to stay in perpetual beta states these days, with production versions hardly in place before a willing world starts fretfully polishing a new revision.

The greatest danger of changes in the geometries of distance and time is the capability they possess to conflict with human comprehension and control. Nevertheless, the promises they hold are numerous, and the opportunities they present already can be felt not just in information systems, but also in the timing and location of the educational process itself.

Educators are migrating from the notion that the process of education should be teacher centered toward a model in 
which it is learner centered. The integration of computing and telecommunication into this process potentially frees school and scholar from the current restraints of place and distance, alters the influence of time, and encourages the integration of distance education into the learning process. In cyberspace, any element of the scholarly process can be centric at any time, or at all points in place and time, whether it be the teacher, the student, or the library collection. That is, every element can be virtual except the socialization process. However, it should be acknowledged that social development is not isolated to the educational institution during an individual's maturation. All of one's growing up is not done in school.

The employment of distance education may well shake apart the fundamental distinctions that have held so long between the locations at which the teaching and learning processes have taken place, and now may dislocate the distinctions between the very institutions that have provided the educational experience itself. The trifocals of K-12, higher education, and continuing education may be transmuted into a lens that is a lineless, seamless, lifelong learning environment. Can we expect a more placeless role for the educational institution? Can we expect a more uniform continuum of education and learning throughout a person's life? Perhaps so.

\section{Distance Information}

Distance education provided in any guise must be supported by appropriate information sources. Libraries will continue to be the primary selection arbiters, organizers, and providers of information for scholarship; and will rely increasingly on remote access as well as the collections at hand to assist their users. Thus, they will rely on both local and distance information.

Distance information is meant to suggest remote access in the broadest of senses. Included in this definition is the application of interlibrary services in all its variations, document delivery in its many manifestations, and the creation and distribution of information objects from a multiplicity of sources. Distance information services are likely to be accompanied by new types of library-provided assistance. These may include regularly staffed, nationally distributed interactive help desks; electronic messaging among librarians and other information professionals, teachers, learners, and mentors; the sharing among institutions of human expertise to provide specialized subject assistance; and the use of information know-bots and Web crawlers using every hour of the day to trawl out information to help the knowledge seeker. "Push services," such as current awareness services before them, are likely to come quickly.

That is, every element can be virtual except the socialization process.

Internet engineers and librarians are striving to mend the inchoate state of the Web. Plans incorporate the concepts of library cataloging and classification schemes into a refinement of the systems that sift the Internet for the most pertinent content relevant to an inquiry. Librarians have assumed a major role in the development and management of tools and content for this new information world. Improvement will be better achieved if everyone involved, librarians and others alike, share a confluent vision and vocabulary.

Despite a great deal of information technology (IT) collaboration, far too many IT professionals are still not fully aware of the importance of librarians to distance education. Distance information is a concept that requires broad discussion and understanding, if for no other reason than to secure the claim of libraries to their necessary role in the distance education process. 


\section{Managed Information}

The inability of libraries and their funding parents to keep up with (1) the continuing escalation of publishing and inflation, (2) the demands for both additional paper-based and digital information, and (3) the requirements for a powerful technical base and advanced human skills to control this information complex has brought about the introduction of completely new schemes for funding and managing the information environment.

Libraries have used cooperative networked arrangements for many years to construct bibliographic databases to effect cost savings and share information, to help meet new service demands and circumvent financial strictures, and as a foundation for other resource-sharing efforts. But most cooperative arrangements in the past have been self-generated by librarians who have seen the wisdom of working together to solve problems-by working from the ground up.

\section{Improvement will be better achieved if everyone involved, librarians and others alike, share a confluent vision and vocabulary.}

As library funding bodies have determined that there is no way to meet the full costs of service demands and rising inflation rates, they have increased pressure on libraries to join in new kinds of consortial arrangements to leverage limited resources-financial, infrastructural, and human - and to provide mechanisms for productivity measurement and accountability. This results in information management from the top down.

To effectuate this approach, information management organizations (IMOs) are being established among libraries just as HMO counterparts have been established in health services. This managed information approach attempts to build a common computer-based and telecom- munications-supported infrastructure through which libraries can share information more easily, participate in consortial information purchases to reduce costs, and coordinate more centrally what has been a very decentralized system of collection building. In addition, this approach is seen as having the virtue of extending the range and depth of information available to each of the IMO participants.

Early in 1996, an article in The Chronicle of Higher Education observed that a growing number of institutions were establishing library consortia "to combine their purchasing power and win better deals" for access to electronic resources. "Statewide efforts already exist in Alabama, Georgia, Illinois, Louisiana, Ohio, Virginia, and Texas," the article notes, "while interstate groups have been formed among Big Ten research universities and among small liberal-arts colleges." ${ }^{3}$

This activity had become so widespread and vigorous that by the fall of 1996, Library Hi Tech had produced an important double issue that detailed library resource-sharing programs in fortysix states. ${ }^{4}$ Describing Web connectivity as a "fundamental empowerment technology," editor C. Edward Wall noted that it had become "an extremely high priority of state libraries, agencies, consortia, legislatures, and offices of the governoracross the United States" in expanding access to information resources. ${ }^{5}$

Most of the organizations that are being shaped across the country seem quite similar to the general model of a topdown, rather than a bottom-up, organization. Libraries appear to have the option of participating in these evolving IMOs. But it is obviously difficult for an institution to choose not to move its regular funding and cooperative energy toward commonly agreed-to, shared programs if it wishes to benefit from IMO seed funding and the other benefits to be gained from consortially scaled partnering. 
Information vendors like this consortial approach very much. It ensures a market; it pretty much guarantees a high level of regularized transactions or licensing income; and it is likely that business transactions will be handled centrally through a representative of the IMO and not through the individual selectors or purchasing agents of every participant.

Sustaining great libraries should not diminish other libraries.

Inherent in such approaches, however, is the fact that libraries inevitably will give up some degree of local choice. Moreover, there is the danger that every participant will be dragged to some midlevel common denominator. The quality of present centers of scholarly excellence may be reduced, unexpectedly promoting the leavening of research resources for haves and have-nots alike. Every library should have the opportunity to lift itself-and to help others lift themselves - to the highest level of technical, collection, access, and service capability possible. Sustaining great libraries should not diminish other libraries. Rather, it adds to, builds up, and enlarges the capabilities of other libraries, and such institutions are themselves strengthened in turn through their collaborative association with others.

There also should be concern that a concentration of information management at a state level, a university system level, or whatever level an IMO functions below the present national cooperative level may well represent a threat to those networked cooperative programs that have served libraries so well for the past twenty-five years. Federating new library cooperative programs could well break apart the present national, networked structure. Rebuilding a national bibliographic wheel on a state-by-state basis would be absolute idiocy. Whether collecting and information-sharing coopera- tives can be established that will not harm the national cataloging metadata structure remains to be seen.

Managed information practices are finding an active place in the contemporary library scene. The concept needs to be incorporated into the library language so that discussions of the serious issues involved can proceed more easily with a fuller understanding of how present resource-sharing practices are evolving from those of the past.

\section{Transformational Budgeting}

The development of IMOs reflects yet another instrument for change that could evolve in the administration of libraries. This provides for the allocation of fiscal and other resources on a different basis than is traditionally the case. This concept is defined in the phrase transformational budgeting.

The capability of institutions, and especially of educational systems or funding authorities overseeing a group of libraries, to influence the directions that libraries will take given the persuasive power of funding is not surprising. The budget process can be used to move libraries through transformational processes they might not otherwise be capable of or care to experience.

There has been a great deal of joking about the difficulty in moving university faculty, or deans, or what have you, toward a common goal-like herding cats, they say. However, there is at least one thing that will herd anything-money. This became abundantly clear during the early days of HEA Title II-C grants, when libraries quickly engaged in cooperative or targeted activities in order to grasp the new funding opportunities directed at strengthening research libraries. This is likely to repeat itself as agencies look toward the use of pooled, rather than individually distributed, funds to support libraries. Federal funds are being directed toward larger-scale digital library initiatives, and telecommunication deregula- 
tion dividends are providing more support for the technical infrastructures of schools, hospitals, and libraries. Funding from the National Digital Library Project at the Library of Congress is driving libraries toward major digitization efforts more quickly than otherwise might be the case.

Economics is encouraging cooperative activity at several levels. Libraries should anticipate experiencing more examples of the application of transformational budgeting at state and system levels. The establishment of IMOs and targeted funding, as described above, will surely be joined by additional similar measures. It is certainly in the best interests of libraries themselves, and of organizations of every sort, to accept (thoughtfully) and use (carefully) the concept of transformational budgeting to help ease the way through the major changes that all are experiencing at such a rapid rate, a rate in which the clocks of change appear to have gone mad.

Transformational budgeting can influence library activity from the top down, but it also can be applied very powerfully at the local institutional level within the library itself. Common sense suggests that every library manager should attempt to direct every possible dollar, every extra dollar added to the library budget toward the solution of problems and not simply toward maintaining the status quo or trying to recapture the lost ground of traditional collections, canceled subscriptions, or downsized staff.

Transformational budgeting should incorporate the dedication of funds for the development and training of staff, and for better informing and educating library users and administrators on the issues that confront libraries today. It should support the enhancement of the computing and telecommunication infrastructure that is required to extend traditional collections through distance information. In addition, it should help make personal access to network computers as ubiqui- tous as possible. Moreover, local resources should be directed toward appropriate institutional participation in IMOs and in transinstitutional, even global, partnerships-for example, in substantial digitization projects; in sharing collections, in shared collection development itself, and in sharing digital information and human expertise.

Many types of resources can be budgeted toward transformation. An attempt should be made to leverage every library dollar, leverage every hour of human labor, use every hour of Greenwich or Web time available, reward every significant staff achievement, and stimulate every creative idea toward progress and quality. Transformational budgeting should be a major strategy incorporated into the tools that library managers can use to address the problems that have seemed so insolvable over the past dozen years.

\section{Conclusion}

Transformational budgeting, distance information, and managed information are themes to include in a new conceptual library vocabulary. They can help libraries understand the changes they face and can provide a context within which the ongoing improvement of library management, programs, and services can be effected while also understanding what may be lost in the process of change.

Understanding something does not necessarily make it good. Libraries face a number of risks in pursuing the practices that lie behind each of these themes. Defining the themes, however, makes them accessible to a reasoned understanding and may enable librarians to better appreciate what these themes can help them accomplish. Such definition also may clarify the possible negative consequences of each theme, which libraries had best keep in cautionary mind.

Change is difficult. Many people are convinced that moving into a new paradigm will result in leaving an Eden behind. The contours of the information 
future are not clear. By nature, librarians require a feeling of control and closure, and the information future today feels as unappreciable as cyberspace itself, much like St. Bonaventure's view of the Absolute: "an intelligible sphere, whose center is everywhere, whose circumference is nowhere."

Ideas have long shadows, but they may not last unless the language that defines them is refreshed for a new era. Ideas may have no more impact than shadows if they are not fleshed out through definition and action. Could we discuss the library issues of today in the more limited language of libraries twentyfive years ago? It is unlikely, and we had better move on with defining fresh conceits in the information present if we are to deal with the issues of tomorrow.

\section{Notes}

1. Harold Billings, "Magic and Hypersystems: A New Orderliness for Libraries," Library Journal 115 (Apr. 1, 1990): 46-52.

2. Peter Lyman, as quoted in William Grimes, "Libraries Ponder Role in the Digital Age," New York Times (Apr. 29, 1996): B1.

3. Thomas J. DeLoughry, "Purchasing Power: Cost-sharing Efforts Help College Libraries Finance Electronic Acquisitions," Chronicle of Higher Education (Feb. 9, 1996): A21.

4. "State of the State Reports: Statewide Library Automation, Connectivity, and Resource Sharing Initiatives," Library Hi Tech 144, no. 2-3 (1996). A useful discussion of five statewide information-sharing consortia may be found in William Gray Potter, "Recent Trends in Statewide Academic Consortia," Library Trends 45, no. 3 (winter 1997): 416-34.

5. Ibid., 8. 